American Journal of Applied Sciences 9 (8): 1232-1236, 2012

ISSN 1546-9239

(C) 2012 Science Publications

\title{
Reliability Centered Maintenance in Schedule Improvement of Automotive Assembly Industry
}

\author{
Rizauddin Ramli and Mohammad Nizam Arffin \\ Department of Mechanical and Materials Engineering, \\ Faculty of Engineering and Built Environment, \\ Universiti Kebangsaan Malaysia, 43600 (UKM) Bangi, Selangor, Malaysia
}

\begin{abstract}
Problem statement: Today, in many automotive manufacturing companies, maintenance management is an important factor to maintain the plant operation and production equipments. Approach: In this study, we present an implementation of Reliability Centered Maintenance (RCM) practice in one of the automotive manufacturing company in Malaysia. The RCM practice was used to assist the company in focusing their maintenance activities based on the criticalities of the equipments by applying the Failure Modes and Effects Analysis (FMEA). The implementation of RCM was carried out in 4 stages; preparation, system analysis, decision making and feedback. The aim of RCM was to reduce the number of maintenance checklist and to improve significantly the integrity of maintenance practice. Results: As a result, the new RCM framework was generated where Class A equipment was at the top of the monthly maintenance frequency priority, followed by Class B and Class C equipment which had lesser critical value. Conclusion: The new RCM framework is used to conduct visible guideline and propose a new maintenance schedule. The guideline is useful for future maintenance strategy improvement. After the implementation, it can be ascertained that our proposed RCM is useful in reducing maintenance personnel burden and this leads to improvement of productivity.
\end{abstract}

Key words: Reliability Centered Maintenance (RCM), Failure Modes and Effects Analysis (FMEA), Preventive Maintenance (PM), Total Quality Management (TQM), Metal Inert Gas Welding (MIG), Decision Making Diagram Tool (DMDT)

\section{INTRODUCTION}

In the last three decades, manufacturing industries had experienced an unprecedented degree of changes such as product specifications, process technologies, supplier attitudes and customer's requirements (Ahuja et al., 2006). This rapid changes environment had forced the manufacturers to enhance and improve effectively their performance by focusing on cost reduction, productivity levels increment, high quality products and prompt deliveries in order to satisfy customers (Balan, 2011). Because of the competitive market, improvement of maintenance strategy and scheduling has attracted manufacturers to adopt decision making tool. Recently, the decision making tool that has been widely implemented is Reliability Centered Maintenance (RCM) that was initially oriented towards maintaining airplanes and used by aircraft manufacturers, airlines and the government (Dekker, 1996). It is a systematic consideration of system functions, failure analysis and a priority-based consideration of safety and economics. RCM is used to identify applicable and effective Preventive Maintenance (PM) tasks (Eisinger and Rakowsky, 2001). It used a structured, logical process in optimizing the maintenance requirements of physical resource in order to realize its inherent reliability. In other words, RCM is a process to determine the maintenance requirement of any equipment in its operating context by identifying the functions of the equipment, the causes of failures and the effects of the failures.

In many automotive manufacturers, Total Quality Management (TQM) and Total Productive Maintenance (TPM) have been largely applied as one of the key factors the successfulness in their maintenance management (Ahuja and Khamba, 2008; Sekine and Arai, 1998). TPM is a production-driven improvement methodology which is designed to optimize equipment reliability and ensures efficient management of plant assets (Haggag, 2009; Moore, 1997).

In this study, we present a case study of RCM implementation in one of automotive manufacturer in Malaysia in order to improve the maintenance scheduling. Initially, all equipments are scheduled with

Corresponding Author: Rizauddin Ramli, Department of Mechanical and Materials Engineering,

Faculty of Engineering and Built Environment, Universiti Kebangsaan Malaysia,

43600 UKM Bangi, Selangor, Malaysia 
routine daily and monthly checklist based on the equipment history record as supporting document. The implementation of RCM is aimed minimize the maintenance personnel checklist and improve the company's maintenance schedule.

\section{MATERIALS AND METHODS}

The case study will covers from body shop, paint shop and trim shops. The body shop has 6 operational production lines and each car model has their dedicated jigs, portable spot welding guns, rivet guns and Metal Inert Gas Welding (MIG), hoists and turntables. All the 6 production lines are identical in equipments but their numbers different according to the process requirement. In the paint shop, all car models are produced in a single production line and any bottleneck in the system will affect the productivity. The line is divided into different zone that deals a different process. Meanwhile at the trim shop, all operations are done manually at 3 main assembly lines which are dedicated to different types of models based on their product sizes and specifications. Here, the machines are not common but $24 \mathrm{~h}$ utilization of overhead hangers, hoists and conveyors make them difficult to maintain. Besides the three shops, the plant also has utility plants that contain air compressors, sewerage plant, waste water treatment plant and a water treatment plant which functioned to support the production line. In this study, in order to achieve our aim to minimize the maintenance personnel checklist, the research was carried out in several stages; the preparation stage, system analysis stage, decision making stage and implementation and feedback stage.

At the beginning of preparation stage, a project group was established from various departments and all relevant equipment documentations are collected such as breakdown reports, maintenance history records, current maintenance checklists, operation manuals, safety incident reports, production and quality reports and service reports from OEMs. Also the equipment was listed accordingly to their respective shop in order to clarify the status of every parts availability.

The next system analysis stage is a process in which brainstorming activities of the project is conducted. Data collected in the first stage was analyzed by using Failure Modes and Effects Analysis (FMEA) tools where all relevant information was examined and verified by the group members. These data are useful as they are the main reference besides experiences from the operators handled the equipment. In the third stage, decision making is carried out to facilitate the new maintenance strategy. Each decision at the job shop level was performed with a decision diagram as aiding tool called RCM Decision Making Diagram Tool (DMDT) as shown in Fig. 1. In this study, we adopted Eisinger and Rakowsky (2001) model as our datum of RCM.
Finally the final stage of RCM is the implementation of the newly proposed maintenance strategy obtained from the previous stage to each shop in the plant. In order to ascertain the effectiveness of the proposed RCM, feedbacks from operators have been collected. Figure 2 shows the process of establishing guideline and proposed new maintenance schedule.

The FMEA has been used to define and eliminate some known or potential failures. Since our case study is a criticality analysis, we defined FMEA as Failure Modes, Effects and Criticality Analysis (FMECA). The main objective of FMEA in this study is to identify potential effects, evaluate and prioritized. So, appropriate corrective actions can be taken for different failure modes which can be determined using Risk Priority Number (RPN) as shown in Eq. 1:

$\mathrm{RPN}=\mathrm{O} \times \mathrm{S} \times \mathrm{D}$

where, $\mathrm{O}$ is the number of the occurrence, $\mathrm{S}$ is the level of severity and D is detection of the failure. These factors $\mathrm{O}, \mathrm{S}$ and $\mathrm{D}$ will be evaluated using rubric scores from 1-4 which indicates the relevancy of the factors to the plant operations. Based on the RPN in Eq. 1, the Equipment Criticality (EC) is calculated based on five factors i.e. number of Failure (OF), Severity of failure to Production (SP), Severity of failure to Safety (SS), Severity of failure to Maintenance (SM) and Detection of the failure (D) as shown in Eq. 2:

$\mathrm{EC}=\mathrm{OF} \times \mathrm{SP} \times \mathrm{SS} \times \mathrm{SM} \times \mathrm{D}$

The factors affecting EC in Eq. 2 is the direct effect during maintenance failure.These factors are important in order to determine the significance level of equipment criticality. All the factors are given weightages or rating ranges from 1 to 4 which indicate less effect, small effect, medium effect and high effect to maintenance failure. Table 1 shows the rating for Occurrence of Failure (OF). Rating 4 is for equipment that fails on daily basis which is very rare in the plant and rating 1 point is given to equipment that is remotely failed.

Similarly, we set the Severity of failure to Production (SP) that is shown in Table 2. The SP relates the criteria and the score respectively. In the rating of $S P$, we consider a situation where a bottleneck condition can be occurred at production lines that have two equal equipments. For instance, tire sub-assembly line is a single production line that has two equal facilities where bottlenecks can be happened when one of the lines is down.

Table 3 shows the rating for SS factor which is related to safety and environmental incident that can be happened during the failure occurs. 


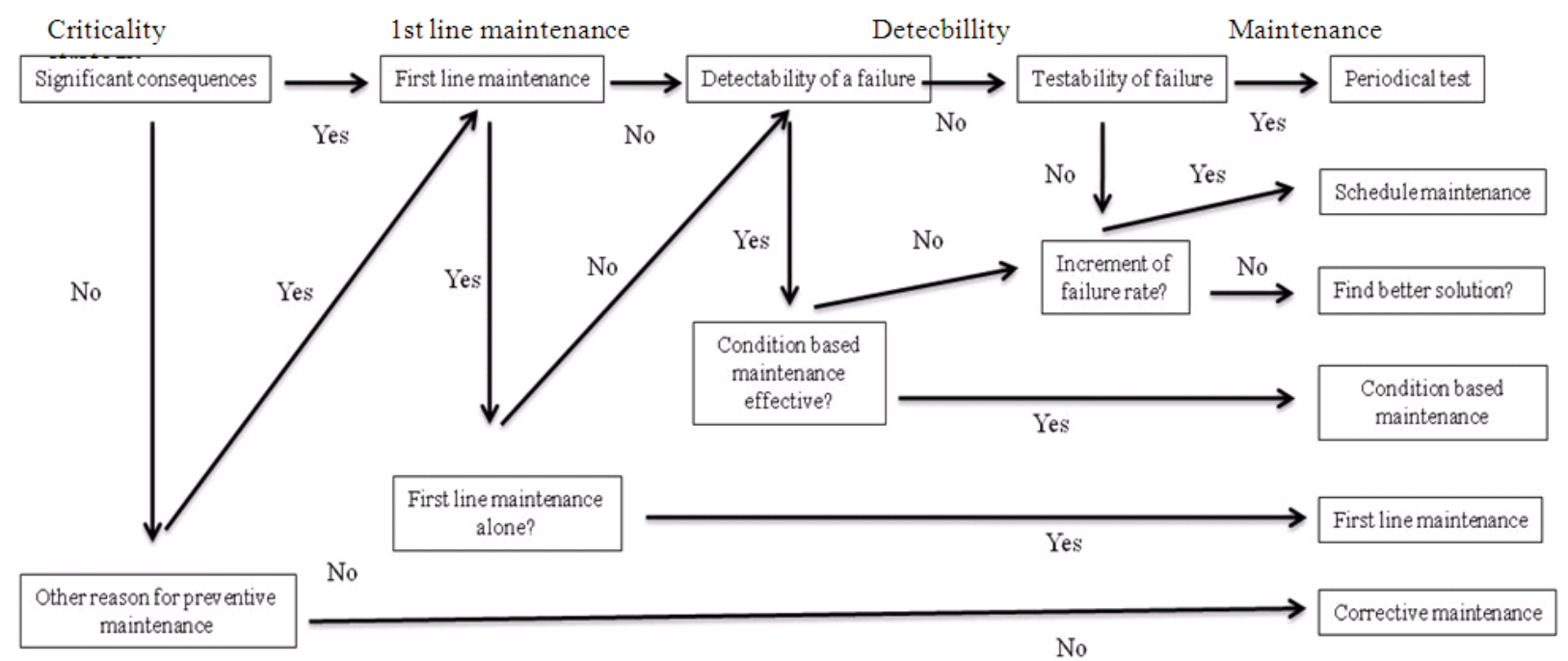

Fig. 1: RCM Decision Making Diagram Tool (DMDT)

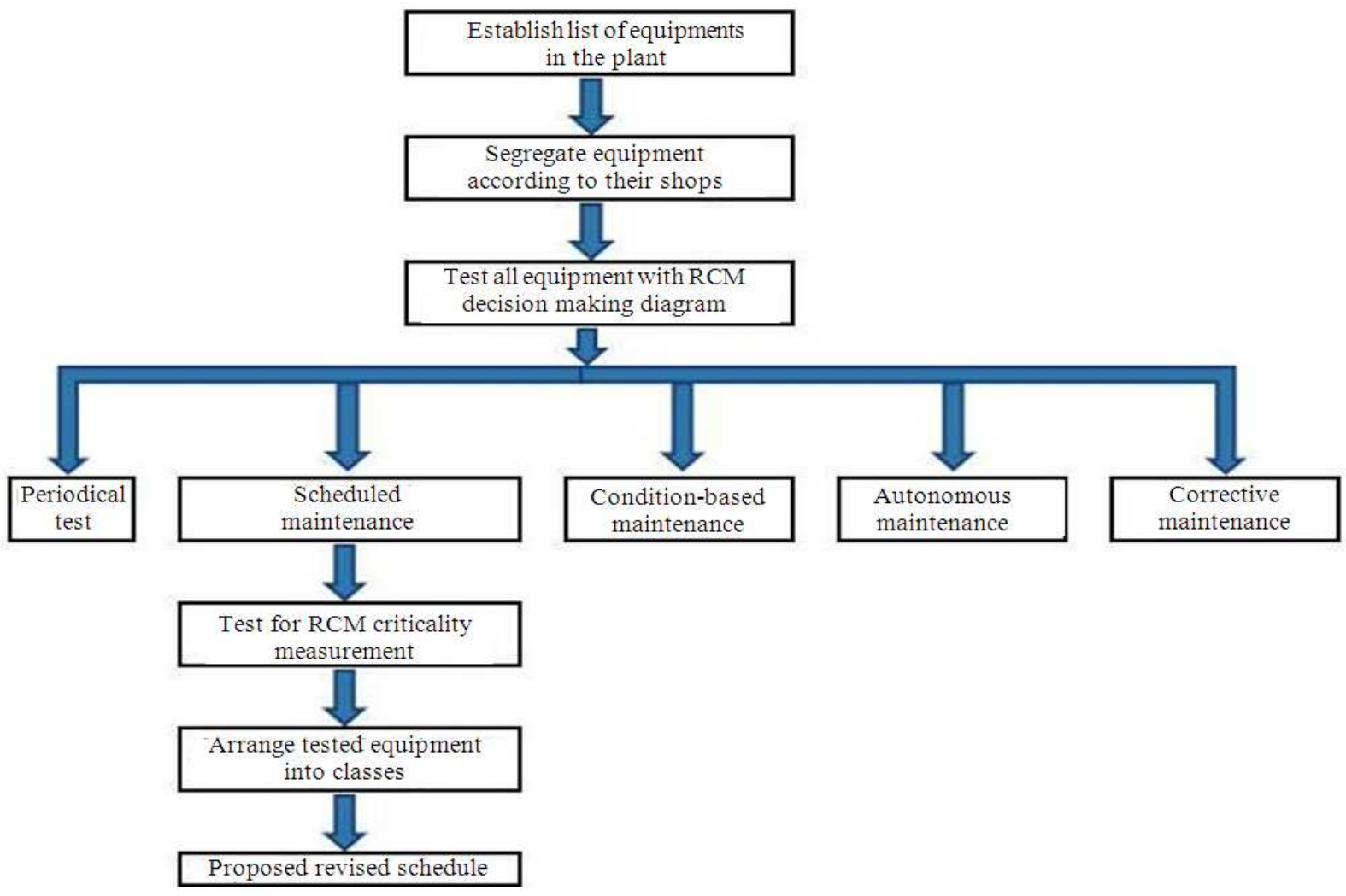

Fig. 2: Process establishment of RCM for maintenance improvement

In this rating the highest is when any human casualty occurs which is rated as 4 points. If the failure causes any accident that affects the lost of personnel working time or LTA, rating 3 will be given. On the other hand, the severity of failure to maintenance is considered as the technical complexity of equipment which is related to the repair time needed by the maintenance personnel. Table 4 shows the rating of the most critical failure will take longer time to repair. 


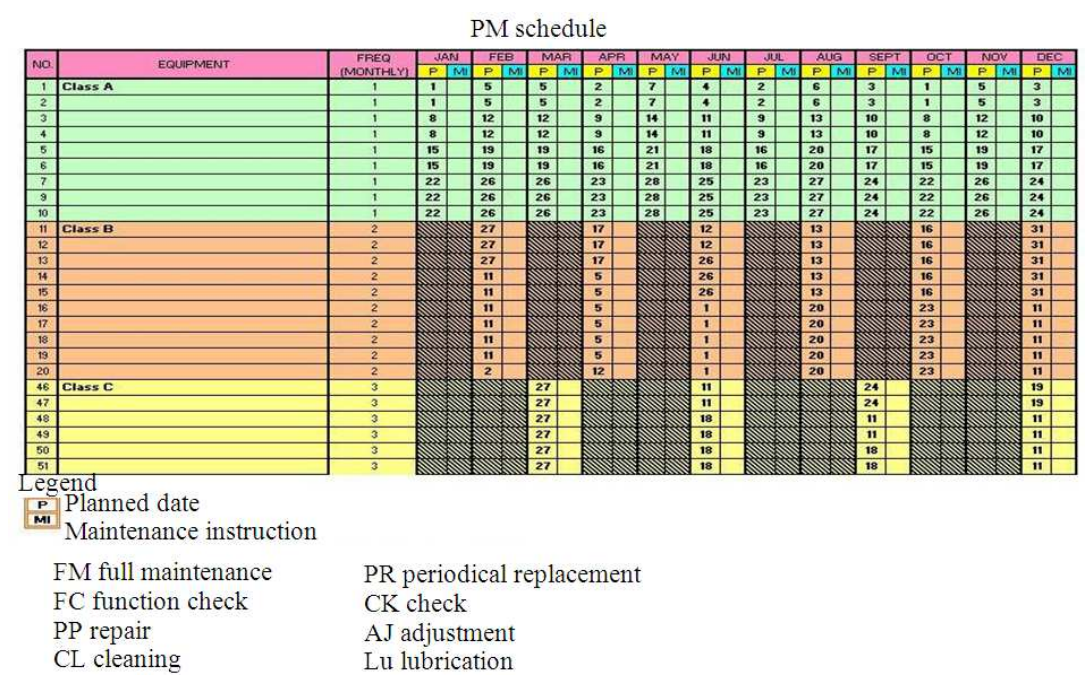

Fig. 3: Equipment classification based on criticality measurement

Table 1: Rating for occurrence of failure, OF

\begin{tabular}{lll}
\hline Rating & Probability of occurrence & Criteria \\
\hline 4 & High & Repeated failures \\
3 & Moderate & Occasional failures \\
2 & Low & Relatively few failures \\
1 & Remote & Failure is unlikely \\
\hline
\end{tabular}

Table 2: Rating for severity of failure to production, SP

\begin{tabular}{lll}
\hline Rating & Probability of severity & Criteria \\
\hline 4 & High & $0 \%$ uptime per day \\
3 & Moderate & $20 \%$ downtime \\
2 & Low & Bottleneck and backlog \\
1 & Very low & Bottleneck \\
\hline
\end{tabular}

Table 3: Rating for severity of failure to safety, health and environment, SS

\begin{tabular}{lll}
\hline Rating & Probability of severity & Criteria \\
\hline 4 & High & Casualty related incident \\
3 & Moderate & LTA related incident \\
2 & Low & $\begin{array}{l}\text { Minor spillage, released of } \\
\text { gasses with no human incident }\end{array}$ \\
1 & Very low & No safety incident \\
\hline
\end{tabular}

Table 4: Rating for severity of failure to maintenance, SM \begin{tabular}{lll} 
Rating & Probability of severity & Criteria \\
\hline
\end{tabular}

\begin{tabular}{lll}
\hline 4 & High & Vendor support with
\end{tabular}

3 Moderate $\quad \begin{aligned} & \text { overseas part sourcing } \\ & \text { Vendor support with }\end{aligned}$

local parts sourcing.

2 Low Internal maintenance support

1 Very low $\quad \begin{aligned} & \text { with fabrication needed } \\ & \text { Internal maintenance }\end{aligned}$

support with spare parts on-hand

Table 5: Rating for detection of failure, D

\begin{tabular}{lll}
\hline Rating & Probability of detection & Criteria \\
\hline 4 & Impossible & Cannot detect point of failure \\
3 & Low & $\begin{array}{l}\text { Lost of primary function. } \\
\text { Difficult to trace failure }\end{array}$ \\
2 & High & $\begin{array}{l}\text { High chance to detect } \\
\text { failure. Common failure }\end{array}$ \\
1 & Almost certain & Visible symptom of failure
\end{tabular}

Finally in Table 5 we rated the detestability of the failure. The highest rating is rated 4 as impossible failure detection while visible symptom of failure will be rate as the lowest rating.

\section{RESULTS}

FMEA test has been used to analyze the criticality of the maintenance practices. The test was conducted as a binary evaluation which is decided as YES (1) or $\mathrm{NO}(0)$ answers. The objective of the test is to measure which is the most appropriate maintenance strategy to be applied to the particular equipment. As results of the FMEA, we found that the maximum score for the equipment determined has the lowest score of 1 and the most critical is 1024 points. Based on the result, we established a guideline to select proper score for the variables and classified the equipments into classes. The equipments were listed in order from most critical (class A) to the least critical (class C). $20 \%$ of the top on the list were classified as most critical, classified as class A equipments, $30 \%$ of the remaining were classified as class $\mathrm{B}$ equipment that have less critical equipment in the plant and the remaining $50 \%$ of the equipment were in class $\mathrm{C}$, i.e., the least critical equipment. Figure 3 shows the example of master PM equipment classification based on criticality measurement.

\section{DISCUSSION}

This study was carried out at one of automotive manufacturing plant in Malaysia which has implemented RCM to improve their current PM task. 
The RCM practice has been implemented directly in order to improve maintenance scheduling and maintenance strategy in their production line. The significance of RCM is proved because it can guide in the selection of maintenance strategy from several relevant maintenance strategies. In our case, during the RCM implementation, all the equipments in the plant were tested according to DMDT. However, in some cases there are equipments that need to be maintained based on their current condition. For example, maintenance of ovens in the paint shop is done through a condition-based maintenance strategy in which the maintenance personnel can monitor the preset and actual temperature of the ovens. If any differences or abnormalities of the system, alarm will be alerted so that the maintenance work or servicing should be carried out.

On the other hand, some equipments need to be as 'first line maintenance. It is a maintenance strategy similar to autonomous maintenance concept of Total Productive Maintenance.

Finally after all the steps followed and realized, a RCM schedule was generated as follows: Class A equipment spares must be kept in the plant's inventory and were at the top of the list with monthly maintenance frequency. Class $\mathrm{B}$ and Class C equipment followed respectively. For lesser critical equipment, the maintenance frequency was reduced to a significant and reasonable frequency. At the end a new RCM framework was established to conduct visible guideline and propose new maintenance schedule. The guideline is useful for future maintenance strategy improvement. It was confirm that the implementation of RCM in this project gave great success and the same methodology can be applied for the whole equipment in the other shop.

\section{CONCLUSION}

In this study, we presented a study of RCM implementation in the PM activities at automotive manufacturing plant. Number of checklist in the body shop has been reduced which resulted to significant reduction of operator's workload and avoided maintenance personnel from committing fraud. The RCM has been used to analyze and perform a decision making process in which maintenance strategy needs to be chosen depends on the criticality of the equipment to the organization.

\section{REFERENCES}

Ahuja, I.P.S. and J.S. Khamba, 2008. Total productive maintenance: literature review and directions. Int. J. Q. Reliab. Manage., 25: 709-756. DOI: 10.1108/02656710810890890

Ahuja, I.S., J.S. Khamba and R. Choudhary, 2006. Improved organizational behavior through strategic total productive maintenance implementation. Proceedings of the International Mechanical Engineering Congress and Exposition, Nov. 5-10, ASME, Chicago, Illinois, USA., pp: 91-98. DOI: 10.1115/IMECE2006-15783

Balan, R.V.S., 2011. Decision based development of productline: A quintessence usability approach. J. Comput. Sci., 7: 619-628. DOI: 10.3844/jcssp.2011.619.628

Dekker, R., 1996. Applications of maintenance optimization models: A review and analysis. Reliab. Eng. Syst. Safety, 51: 229-240. DOI: 10.1016/0951-8320(95)00076-3

Eisinger, S. and U.K. Rakowsky, 2001. Modeling of uncertainties in reliability centered maintenance-a probabilistic approach. Reliab. Eng. Syst. Safety, 71: 159-164. DOI: 10.1016/S0951-8320(00)00088-0

Haggag, M., 2009. Cost analysis of a system involving common-cause failures and preventive maintenance. J. Math. Stat., 5: 305-310. DOI: 10.3844/jmssp.2009.305.310

Moore, R., 1997. Combining TPM and reliabilityfocused maintenance. Plant Eng., 51: 88-90.

Sekine, K. and K. Arai, 1998. TPM for the Lean Factory: Innovative Methods and Worksheets for Equipment Management. 1st Edn., Productivity Press, Portland, ISBN-10: 1563271915, pp: 360. 